\title{
El Maestro y su oficio ${ }^{51}$
}

\author{
Alonso Takahashi \\ Universidad Nacional de Colombia
}

Una tarde, hace casi 2.400 años, tuvo lugar, en Atenas, la más célebre conferencia de la antigüedad.

El conferenciante era Aristocles, más conocido como Platón, y la exposición versaba sobre lo Bueno $\mathrm{o}$, en términos que quizás se consideren hoy más platónicos, el Bien.

El relato no debe ser tomado al pie de la letra pues proviene de Aristóxeno, de quien es conocida cierta antipatia hacia Platón, para no hablar de su manifiesto gusto por el chisme y la maledicencia.

Sea como sea, parece que en el lugar de la conferencia se congregó la flor y nata de la intelectualidad ateniense. Asistieron los alumnos de la Academia y, naturalmente, los principales discipulos de Platón. Alli estaban Xenócrates, quien escribiria una obra sobre la vida del maestro; Espeusipo, su sobrino y sucesor en la dirección de la Academia, Heráclides Póntico, el atomista y cosmólogo y, por supuesto, el fiel Aristóteles.
Es ésta la única disertación pública que se le atribuye a Platón. Hace parte de su controvertida doctrina inédita, sobre la cual no dejó, o no nos ha llegado, nada escrito. Hay, no obstante, razones para pensar que algunas de las tesis expuestas en ella aparecen en el Filebo. También es posible que las lecciones sobre este diálogo, ofrecidas por Marsilio Ficino en su academia neoplatónica de Florencia, fueran inspiradas en al conferencia de Platón. Aristóteles consignó su versión en un tratado de tres libros titulado Sobre lo bueno, un ejemplar del cual llegó hasta Alejandro de Afrodisias, en el siglo III de nuestra era. Desde entonces sólo aparecen algunas referencias en los escritos de sus discipulos.

Según Aristóxeno, al correrse la voz de que Platón disertaría "sobre lo bueno", se reunió una multitud proveniente de Atenas y sus alrededores esperando recibir indicaciones prácticas sobre cómo lograr bienes; como el poder, la riqueza, la salud y, sobre todo, la dicha y el placer. Pero cuando el conferenciante empezó a hablar de matemáticas -de aritmética, geometría y

${ }^{51}(\mathrm{NdE})$ Palabras pronunciadas en el acto de entrega del Premio Nacional de Matemáticas 1991. Este texto fue publicado inicialmente en la Revista Universidad Nacional número 26, abril de 1992, pp. 19-26. 
astronomia- la sorpresa y el desconcierto fueron generales, algunos no ocultaron su enojo y se retiraron sin disimulo mientras que otros, más discretos, empezaron a escurrirsé de manera gradual. En resumen, la audiencia fue sometida a una exposición árida y supremamente técnica en la cual se exploraban avanzadas tesis pitagóricas y se proponian los lineamientos de una ontología matemáticamente fundamentada en la cual se identificaba el Bien con la "clase de lo determinado, concebida como unidad". Dada la admiración que Platón tenía por las matemáticas y el lugar preponderante de la idea del Bien, en la jerarquía de las formas, como fuente de todo lo bueno y todo lo cierto, éste pudo ser un intento de fundamentar simultáneamente el Bien y el Uno, el orden moral y el orden intelectual. Tan audaz identificación entre virtud y conocimiento había sido en realidad una tesis socrática en la confrontación con los primeros profesionales de la enseñanza: los sofistas.

La reunión, como ya habrán podido ustedes inferir, fue un rotundo fracaso. Pero, sea por ésta o por otra razón menos adversa, la conferencia se hizo famosa en el mundo antiguo.

Diógenes Laercio, quien en su Vidas de los filósofos más ilustres no desdeñó recoger cuanta habladuria llegó a sus oidos, cuenta, en lo que parece ser otra versión de la misma historia, que sólo Aristóteles se quedó hasta el final. Si hemos de confiar en el juicio del historiador contemporáneo Indro Montanelli, quien, quizás sea oportuno decirlo, tiene también una lengua viperina, su actitud no se debe atribuir sólo a la admiración y al respeto. No quería perderse ni una sola palabra de Platón, pues ya estaba preparando su propio sistema filosófico, en el cual se proponía refutar todas y cada una de las doctrinas del venerado maestro. Podríamos pensar que Aristóteles se adelantó así a Popper en la identificación de los tres niveles de placer que brinda toda tesis o demostración que se nos propone: el primero es entenderla; el segundo, más noble que el primero, es poder repetirla; y el tercero y superior consiste en ser capaz de refutarla. Sin embargo, el que ésta fuese una de sus historias favoritas, después de la muerte de Platón, no deja de sugerir interpretaciones menos benevolentes. Valga el comentario para que los conferenciantes nos cuidemos, o nos alegremos, de los asistentes muy asiduos a nuestras exposiciones.

Sobra por supuesto decir que, al evocar tan notable acontecimiento, no he querido insinuar ninguna especie de comparación. Ello seria no sólo una impertinencia sino una ingenuidad inconcebible. Esto no significa, sin embargo, que no haya relación alguna entre esta introducción y el tema que me propongo desarrollar.

Teniendo en cuenta el motivo de mi participación en este acto, podría esperarse que hablase de matemáticas, y quizás sólo de matemáticas. Pues bien: no trataré ningún tema específico de matemáticas. Esta suerte de antisemejanza es la primera razón. La segunda es que, en cierta forma, voy a referirme a lo bueno y a la virtud. Una tercera razón es que, hasta cierto punto, me identifico con esa lejana audiencia, y que la historia en sí me parece divertida e instructiva. Dos cualidades que deben acompañar la buena docencia. Además, uno nunca se resiste a repetir un buen cuento, asi éste haga parte de la historia antigua.

La segunda de estas razones requiere algún comentario. Bastará con decir cómo llegué al tema de esta alocución: cuando se me comunicó el otorgamiento del premio nacional de matemáticas sentí una vaga disconformidad cuya 
causa no me fue difícil localizar. No deseaba dejar flotando la idea de que estaba aceptando esta distinción como un reconocimiento a presuntos aportes en el campo de la investigación matemática, los cuales, en mi caso, y sin falsa modestia, considero escasos y de menor importancia. Sólo tenía posibilidades de justificación se la refería a mis esfuerzos por ser un buen maestro. Este es un empeño que siempre he tenido presente y en el cual creo haber logrado algunos resultados parciales, aunque nunca tantos como hubiese querido. Pero, aún en este campo, subsisten dudas e interrogantes. Para empezar, ¿qué es un buen maestro?

Buscando una respuesta algunos recurren a la sentencia bíblica: por sus frutos los conoceréis. Pero otros objetan que, según esto, un buen maestro es quien tiene la suerte de tener buenos alumnos. Todos, sin embargo, coinciden en que la mera posesión del conocimiento no hace al buen maestro, aunque quizás también todos estén de acuerdo en que nadie puede enseñar lo que no sabe. Frente a este viejo problema recordé una referencia de Felix Browder a la identificación entre virtud y conocimiento en la antigua conferencia de Platón, y quise aprovechar la ocasión para explorar sus implicaciones en el caso de la enseñanza.

La verdad y el bien están seguramente relacionados ya que ambos dependen esencialmente de nuestra racionalidad. Además, como alguna vez dijera Huxley, debemos conocer lo que es cierto para poder hacer lo que es justo. Esto no quiere decir que lo bueno se manifieste sólo en el conocimiento. La pregunta ¿qué es un buen maestro? No tiene una respuesta fácil e inmediata, aunque tampoco parece inabordable o antinómica. Eso puede indicar que es una pregunta legitima. Para contestarla hay que pensar en la función del maestro, en su oficio, y ello nos lleva de nuevo a los griegos y su noción de areté.

La palabra griega areté se traduce ordinariamente como virtud; pero este término no mantiene su significado original. Para los griegos tenía un alcance que no coincide con el de virtud en el sentido de honradez, templanza o santidad. En la areté griega había una connotación de pericia y calidad que aún subsiste en una de las acepciones de la palabra virtuoso. Se aplicaba a las profesiones y oficios haciendo referencia al desempeño óptimo de sus funciones propias. Era, si se quiere, un concepto relativo. Después, su significado se hizo extensivo a la areté del ciudadano en general y hasta del ser humano como tal. Se le buscó un significado absoluto y se incorporó a la idea platónica del Bien. Pero la areté tenía originalmente un sentido más concreto y particular que acentuaba su significado práctico y aplicación inmediata. Se hablaba por eso de la areté de los atletas, de los artesanos, de los políticos, de los militares, y hasta de los esclavos. Habia una areté social y una areté doméstica. Hoy hablamos de optimización, de eficacia y de eficiencia: eso también habría sido areté. En una palabra, era la búsqueda de la calidad en el desempeño de una profesión u oficio. El pecado contra la areté era la incompetencia, la ineptitud, la inexperiencia, la ignorancia. En este sentido la areté no significaba en un principio ser bueno, a secas, sino ser bueno en algo, ser bueno para algo. Ser hábil en su tarea, sea cual fuere. Hacer aquello que se espera de uno, aquello que le corresponde hacer, según su suerte y condición, y llevarlo a cabo de manera óptima. Buscar la excelencia en su trabajo, la maestría, el profesionalismo. Conocer bien su oficio y hacerlo con propiedad. Con exactitud y también con rapidez.

Es así como la areté tiene que ver con la exactitud pero no es la manía del detalle insignificante. 
También tiene que ver con la rapidez pero no supone precipitación ni apresuramiento. Sobre este punto quiero detenerme un instante. Es posible que la inteligencia sea una forma de rapidez. Contando con suficiente tiempo una ameba puede llegar a la teoría de la relatividad. En realidad eso fue lo que sucedió. Pero para que tenga sentido terrenal hay que tener en cuenta la escala de la vida humana. Sin embargo, aun dentro de la brevedad de nuestra existencia, hay muchas tareas que tienen su periodo de maduración. Todo lleva su tiempo. La areté tiene que ver con la preparación y el adiestramiento para la ejecución de una tarea. Esta preparación variará en duración y modalidad según el caso. Hay un cuento mencionado por Calvino a propósito de la rapidez: el rey le pidió a Chuang Tzu (Zhuangzi) que dibujara un cangrejo. Chuang Tzu contestó que necesitaba cinco años y una casa con doce servidores. Pasaron cinco años y Chuang Tzu dijo al rey: "Necesito otros cinco años" y el rey se los concedió. Transcurridos los diez años, Chuang Tzu tomó el pincel y con un solo trazo dibujó un cangrejo, el cangrejo más perfecto que jamás se hubiera visto. Me gusta pensar que esos diez años los pasó Chuang Tzu preparándose para su tarea. Y que su arte no murió con él, porque ese hombre, que una noche soñó que era una mariposa y al despertar no sabía si era un hombre que había soñado que era una mariposa o una mariposa que estaba soñando que era un hombre, era sobre todo, un maestro. Pero ésta es sólo una fábula. Ya en la realidad podemos recordar que Max Planck tardó veinte años elaborando la teoría de los cuantos. Pero fue el primero en lograrlo. También le tomó veinte años a Bernouille descubrir, formular y demostrar la ley de los grandes números. Y Borges nos cuenta que, cuando a james Whistler le preguntaron cuánto tiempo había requerido para pintar uno de sus nocturnos, respondió: "Toda mi vida". Esa es la rapidez a la que me refiero.
Ahora podemos aceptar con más naturalidad la afirmación de que la virtud, la areté se puede adquirir. Es posible que la calidad no sea más que la perseverancia en la búsqueda de la excelencia. No es un don dispensado a unos pocos. Requiere conocimiento y la correcta comprensión de su objetivo. Implica esfuerzo, requiere práctica y dedicación, y eso lleva tiempo. Después de estas consideraciones generales hay que empezar a particularizar pues parece que el oficio del profesor de matemáticas tiene rasgos muy peculiares.

Señalemos en primer lugar que tanto profesional como profesor viene de profesar que significa consagrarse voluntariamente al ejercicio de una ciencia, arte u oficio. El oficio del maestro, del profesor, es preparar a otros para cumplir su función, ayudarles a lograr su areté. Y como no todos van a ser a su vez maestros, su camino no es necesariamente el recorrido por él. Además, el maestro debe ser capaz de reconocer y cultivar en otros, cualidades de las cuales él mismo puede carecer. No debe extrañar entonces que formar un buen maestro requiera un tiempo considerable. Uno de mis colegas ha dicho que la prisa, sobre todo en educación, es un pecado. Esto es algo que la sociedad y sus instituciones deberian mantener siempre presente. Por eso me detuve un poco al hablar de la rapidez.

Empezamos a ver que la areté del maestro, del profesor, tiene en verdad rasgos especiales. Como todas las profesiones, la profesión docente ha sido difamada y exaltada. Nietzsche, profesor de filosofía, escribió que el profesor es un mal necesario. Es célebre la alusión de Oscar Wilde a los que no pudieron aprender y por eso se dedican a enseñar. Otro colega me dio alguna vez una versión aún más mordaz: el que sabe hace, el que no sabe enseña, el que no puede enseñar investiga y el que no es capaz de investigar se dedica a enseñar a investigar. Son sin duda frases 
satíricas, cuya crítica se localiza sobre todo en la incompetencia $y$, aunque tengan su fondo de verdad, no son censuras a la docencia como tal y mucho menos a la profunda relación entre maestro y aprendiz.

La verdad es que, desde hace ya bastante tiempo, la importancia dela profesión docente ha sido reconocida ampliamente por la sociedad. En los discursos de los gobernaste no se ahorran palabras de encomio a la trascendencia de nuestra labor. Eso sí, cuando se plantea el problema dela mejora de las condiciones materiales de los maestros, se apela a virtudes como la nobleza y la abnegación.

El oficio del maestro es enseñar. Enseñar es señalar, mostrar, indicar la ruta. Hay que dar a los alumnos la oportunidad de transitar su propio camino y encontrar las cosas por sí mismos. Cada vez que entregamos a un alumno un conocimiento ya elaborado y decantado, le estamos quitando la oportunidad de descubrirlo. Lo importante es enseñar a aprender. En ello entra en juego la memoria y también el olvido. A menudo el maestro debe olvidar lo que sabe para que el alumno lo descubra. Para Heidegger enseñar es más dificil que aprender porque enseñar significa dejar aprender. Más aún: el verdadero maestro no deja aprender nada más que "el aprender". Por esto también su obrar produce a mendo la impresión de que propiamente no se aprende nada de él, si por "aprender" se entiende nada más que la obtención de conocimientos útiles. Lo esencial en el aprendizaje no es el producto sino el proceso. Lo mismo ocurre con la creación de conocimiento. Leibniz decia que las fuentes de la invención son más interesantes que las invenciones mismas. Las ideas deben nacer en la mente del alumno, sostenía Sócrates. El aprendizaje no debe ser pasivo. Hay un proverbio que dice: Oigo y olvido; veo y recuerdo; hago y entiendo. Entender es más un hacer que un contemplar. Además, para que sea efectivo, el conocimiento no debe consistir en ideas a medio entender y aisladas unas de las otras. Las ideas inertes, las ideas que no interactúan entre sí, no son sólo inútiles: son perjudiciales.

Estas consideraciones plantean un problema. La extensión de los conocimientos acumulados por la humanidad, unida a las necesidades para la vida y el progreso de la sociedad, imponen una selección de temas y de métodos. Este, de por sí, es un asunto de mucha complejidad y extensión, el cual no voy a tratar. Recordemos sí que método significa camino $y$, como tal, no es necesariamente único.

Si queremos avanzar un poco más tenemos que particularizar el campo del conocimiento objeto de la enseñanza. Aunque hay casos excepcionales, un buen maestro supone una honda compenetración con la naturaleza del conocimiento que desea comunicar. También en este aspecto el campo de las matemáticas presenta sin duda características muy especiales.

Habiendo adquirido sus rasgos esenciales en la antigüedad, la matemática se desarrolla a lo largo de casi tres milenios; en esta larga historia, sin parangón en otras ciencias, ha acumulado enormes avances tanto en extensión y versatilidad como en profundidad y refinamiento.

La importancia de la matemática en la sociedad moderna se refleja en su presencia a lo largo de toda la escala educativa, así como en la vida cotidiana, en la administración y en la tecnología. En las ciencias, tanto naturales como sociales y económicas, la matematización es índice de madurez y estructuración.

Como parte integral del pensamiento racional, la matemática es uno de los pilares de la 
civilización, sólo comparable en importancia con el lenguaje, con el cual, dicho sea de paso, guarda estrechas relaciones.

Crear, apreciar y utilizar la matemática no pueden disociarse de manera radical pues son facetas de la actividad matemática general del hombre. Matematizar, en este sentido amplio, comprende producir y consumir matemática, hacerla, usarla y disfrutarla. Como tal es una característica primordial del entendimiento humano. Tiene en común con el arte un aspecto lúdico en sus origenes, y la búsqueda permanente de patrones estéticos. Tiene raices en necesidades prácticas de medición, cálculo y predicción. Se desarrolla a impulsos de la curiosidad, el gusto por la belleza y la tentación de los problemas. Recurre constantemente a la experiencia, la conjetura y la imaginación, pero se somete voluntariamente a las reglas de juego del razonamiento válido. Es una ciencia y a la vez un arte.

Galileo escribió en Il Saggiatore, que la naturaleza es un libro abierto pero escrito en lenguaje matemático. Este lenguaje es también la clave para comprender gran parte del mundo humano. Su gran poder de unificación lo convierte en un formidable recurso de la mente para el estudio de la realidad objetiva.

Señalar caminos en este vasto campo intelectual es sin duda una tarea compleja y de gran responsabilidad. Ahora vemos por qué la formación del maestro de matemáticas no puede ser apresurada. Si en la educación en general la prisa es un pecado, en la educación matemática ese pecado es mortal.

Con el fin de discutir el oficio del maestro de matemáticas con algún orden distinguiré tres aspectos que tampoco se pueden separar.
Corresponden a lo que he descrito como la creación, la utilización y la apreciación de la matemática. Me refiero a la enseñanza de la matemática en sí misma, como herramienta y como componente de la cultura. El tema de la formación de los maestros, de los que van a enseñar, permanece siempre en el trasfondo pues en él deben confluir los tres aspectos de manera armoniosa.

Sobre la formación de nuevos matemáticos sólo diré que, aunque localmente pueden existir circunstancias adversas, de índole social y económica, propias del grado de desarrollo de cada país, parece que, en general, los matemáticos están en condiciones de reproducir su propia especie. Algunos piensan que su celo es incluso excesivo, pues, cuando tienen la oportunidad de intervenir en el diseño de programas, parecen obrar bajo la hipótesis de que todos los estudiantes, y no sólo una infima fracción, van a ser matemáticos. Se olvida incluso que la mayoría de los mismos estudiantes de matemáticas van a ser profesores no investigadores y que un programa orientado a formar muy buenos profesores causa menos frustraciones y puede producir, por contera, excelentes matemáticos. En todo caso, se trata de un campo en el cual se tiene cierta claridad sobre lo que hay que hacer, aunque subsistan conflictos de valores como el mantenimiento de escalas de excelencia para uso doméstico, el encauzamiento de jóvenes en líneas sin porvenir o la presión indebida ("publicar o perecer") que tiende a desvirtuar la producción intelectual. A este respecto alguien proponía que, a su ingreso al cuerpo docente, los jóvenes fueran nombrados profesores titulares con sueldo máximo y que, de alli en adelante, se les rebajara el sueldo por cada publicación. Así sólo publicarían cuando tuviesen que decir algo tan importante que justificara el sacrificio. Pero estas situaciones tienen, en las sociedades abiertas, sus 
propios mecanismos de control. Al final la confrontación es inevitable y el último juez será la comunidad matemática internacional. Por eso es flaco el servicio que se presta cuando se rebajan demagógicamente los estándares y se diluye la crítica. Propiciar el autoengaño es por lo menos tan inicuo como desestimar el talento.

Más aún, se puede preguntar, por ejemplo, si la matemática tiene en realidad un valor intrinseco que justifique que a ella se dediquen muchas de las mejores mentes de cada generación. Pero estos son asuntos que quizás no sabemos ni siquiera cómo formular con propiedad.

El segundo aspecto es el de la enseñanza de la matemática para quienes la necesitan, aunque no van a ser ni matemáticos ni profesores de matemáticas. La enseñanza en este campo afronta problemas delicados que derivan, en parte, del énfasis exagerado sobre aspectos insustanciales, principalmente formales, especulativos y terminológicos. También aquí se puede plantear una cuestión ética pues, aunque existan deficiencias en la formación básica del profesor, el problema se agrava al seguir el camino del menor esfuerzo. Repetir cadenas de definiciones y demostraciones que se chequean paso a paso, es fácil. Mucho más difícil es demostrar las ideas fundamentales que estructuran un desarrollo, su génesis y evolución. Analizar a fondo un enunciado para entender lo que dice y lo que no dice, su motivación y su razón de ser, sus consecuencias y sus limitaciones. Dar una idea global del tema, su arquitectura y sus conexiones con otros campos.

Pero aunque subsistan problemas serios, hay también una creciente conciencia de ellos y de sus causas. Entre éstas hay que señalar el aislamiento producido al cercenar las conexiones con otros campos, la fragmentación producida por la excesiva especialización en niveles tempranos de formación y la exclusión de las humanidades, y hasta de las otras ciencias, de los programas de estudios. Pero esto nos conduce naturalmente al tercer campo de acción del profesor de matemáticas: la enseñanza de la matemática como componente esencial de la cultura.

Esta anomalia es especialmente notoria en las carreras técnicas, donde las matemáticas son sólo un filtro y, ni siquiera en las áreas profesionales, se muestra su verdadera razón de ser.

En el caso específico de las aplicaciones, es frecuente la consideración de situaciones artificiales en donde la matemática no juega un papel genuino. Esta matemática, teóricamente aplicada, es sólo una mixtificación. El resultado ha sido caricaturizado magistralmente con base en otra fábula de Chuang Tzu: deseando convertirse en cazador de dragones, un joven ingresó a una escuela especializada en este arte milenario y durante cinco largos años estudió sin descanso hasta obtener su grado. Durante muchos meses vagó en busca de dragones para cazar y, al no encontrar ninguno, fundó una escuela y se dedicó a enseñar a otros a cazar dragones. Es posible que toda su vida siguiera creyéndose un cazador de dragones.

En gran parte este campo es sólo un nuevo aspecto de los dos anteriores, sobre todo del primero. A menudo, tanto en la ciencia como en el arte, la creación es contrapuesta a la apreciación. Se ha dicho, sin embargo, que el acto creador consiste en descubrir semejanzas ocultas, hallar la unidad en la diversidad. No olvidemos que teorema significa visión: una vez creados, señalaba Bronowski, tanto el cuadro como el teorema pasan a ser patrimonio de todos. Con el acto de apreciación, de comprensión, cada 
hombre puede, en principio, recrearlos, reproduciendo por sí mismo una parte esencial de la experiencia original.

Como ejercicio de la imaginación, del sentido estético y del pensamiento abstracto, la matemática es una parte fundamental del acervo cultural del hombre. Sin embargo, el matematizar está circunscrito a una comunidad reducida que no ha logrado verter con amplitud sus experiencias al resto de la humanidad.

Es lamentable que a la mayoria de la gente le esté vedada toda una dimensión de experiencias intelectuales y estéticas. Todos los seres humanos pueden admirar la perfección de una orquidea o el esplendor de una noche estrellada, muchos pueden llegar a apreciar la belleza de un cuadro, disfrutar de una sinfonía y asombrarse al comprender a grandes rasgos la estructura del átomo, la evolución de las estrellas o los mecanismos de la herencia, así como la historia de esas conquistas. En cambio consideran la matemática como una ocupación inaccesible al común de los mortales o, lo que es peor aún, la ven como una disciplina esotérica o como una rutina que usa simbolos abstractos para efectuar cálculos interminables. Su actitud, como la de muchos de los oyentes de Platón, es entonces de obnubilación, indiferencia o resignación, cuando no de aversión, desdén o terror.

Hay, sin duda, causas intrínsecas que no se pueden soslayar sin faltar a la verdad. Y no hablo del gran descubrimiento matemático que supone altas dosis de imaginación, perspicacia, creatividad y dedicación.

La matemática es, entre otras cosas, un lenguaje muy preciso y no enteramente reducible al idioma corriente; en ella podrá haber verdadera poesía, pero es poesía escrita en un lenguaje altamente especializado. Un lenguaje que requiere cierto simbolismo y abstracción y en el cual no puede recurrirse libremente a la analogía y a la metáfora sin riesgo de traicionar el significado. Su ejercicio y aun su apreciación exigen por ellos cierto esfuerzo intelectual.

Pero estas condiciones no son privativas de la matemática. La apreciación de un arte mejora notablemente con el aprendizaje de su lenguaje propio. Y si bien no todos podemos llegar a componer una pieza musical, muchos pueden entenderla, disfrutarla y hasta reproducirla. Cualquier esfuerzo por abrir el campo de la matemática para que un mayor número de personas pueda entenderla, apreciarla y conocer y discutir con propiedad su papel en la civilización, está plenamente justificado.

Parece, sin embargo, que las causas extrinsecas son más determinantes, a pesar de que ellas pueden, en principio, ser controladas. Tenemos, en primer lugar, la enseñanza que distorsiona la naturaleza de la matemática. Bajo la ficción de poseer la clave del conocimiento matemático se han preconizado enfoques que se regodean en trivialidades y escamotean todo vestigio de sustancia. Enmascarando la superficialidad con un pretencioso aparato de símbolos y de terminología, asociados a conceptos huecos y distinciones pedantes e infecundas, llevan al educando a un estado de enajenación o de indiferencia. Los excesos en esta materia han sido denunciados en varias oportunidades. René Thom, por ejemplo, señala que la manipulación mecánica de operaciones lógicas lleva a considerar incongruencias como el conjunto de los "cubos grandes o azules", que le habrían producido un trastorno a Platón, y que no son sólo ejercicios extraños e inútiles sino que podrian llegar a ser un peligro para el equilibrio mental, pues, al mezclar campos semánticos 
ajenos, rayan en lo que técnicamente se llama delirio.

Es manifiesta además, cierta tendencia a ignorar la evolución general del conocimiento embebiéndose en cambio en definir, parcelar y delimitar meticulosamente el campo de la matemática. Se cortan asi sus raíces y sus vínculos con otros campos del saber, dejando sólo un esqueleto, desarmado y vuelto a armar de manera extravagante y del cual se ha escamoteado casi toda la osamenta original.

La matemática no es ajena al conocimiento de la naturaleza y, como parte del saber humano, no puede separarse de la cultura. El cultivo de la matemática no puede hacerse sacándola de su contexto científico y cultural y presentándola de forma aséptica y aislada.

La estrechez de la formación no se manifiesta sólo en relación con las humanidades sino también con el resto de las disciplinas científicas. El primer problema es general y no es nuevo. C.P. Snow, en Las dos culturas, ilustra la incomunicación entre humanistas y científicos: un invitado a un banquete en Cambridge encuentra que sus compañeros de mesa sólo hablan entre sí y, cuando se dirige a ellos, le contestan con gruñidos. Finalmente uno de sus colegas humanistas, que ha advertido su desconcierto, se acerca y le tranquiliza diciéndole: ";Esos son matemáticos! Con ellos no se puede hablar".

$\mathrm{El}$ segundo, un poco menos frecuente y agudo que el primero, parece no obstante estar ganando terreno a la sombra de la inevitable tendencia a la especialización. Es posible imaginar un gran matemático que no se preocupa por la naturaleza de la matemática y le tiene sin cuidado su relación con otras ciencias y con la cultura. Pero en un profesor de matemáticas esto no puede tener justificación.

Si la fragmentación es en sí preocupante, más lo es cuando la especialización se define no por lo que sabe sino por lo que se ignora. Ustedes me entienden: que yo sea especialista en álgebra topológica, por ejemplo, no significa que sepa mucho de este recóndito tema sino que no sé nada de los otros.

Para empezar su carrera el joven profesor de matemáticas debe contar con esa seguridad que sólo puede provenir del genuino sentimiento de dominio sobre algunas ideas y procedimientos básicos. No tienen que ser muchos, pero tiene que conocerlos bien. Además de la confianza que emana de saber algo y saberlo bien, debe tener la aptitud de continuar su formación a lo largo de toda su carrera. Una carrera que lo llevará a participar en la formación matemática de personas con las orientaciones más diversas y también en la formación de futuros profesores de matemáticas.

Mientras más amplio sea su campo de acción, mayores serán las exigencias a su formación. Entre esas exigencias hay una de especial importancia: Aunque la matemática es en cierta forma un lenguaje, la comunicación sigue dependiendo del adecuado manejo del lenguaje ordinario. Todo profesor, y en especial el de matemáticas, debe poder expresarse con fluidez y precisión. La importancia y la profundidad de un tema no riñen con el lenguaje sencillo y claro. Lo que no se puede decir con claridad es mejor no decirlo. Todos estos requisitos se acentúan cuando, abordamos el problema de la comunicación con el público en general. Esto me lleva al último tema de mi exposición.

Se trata de uno de los grandes desafíos a la comunidad científica y a la vez una de sus 
mayores tentaciones. Me refiero a la divulgación. No la divulgación que, como dice Wittgenstein en su Conferencia sobre ética, consiste en hacerle creer al público que entiende algo que realmente no entiende, satisfaciendo esa curiosidad superficial acerca de la ciencia que encubre la indiferencia más profunda.

La divulgación debe navegar ente el Escila de la especialización abstrusa y el Caribdis de la generalidad insustancial. Entre lo incomprensible y lo incorrecto. Entre los tecnicismos indescifrables y las falsas metáforas. No hay duda de que toda comunidad especializada experimenta dificultades en su comunicación con el público en general. Pero mientras científicos como los físicos, los biólogos y los astrónomos logran despertar interés genuino por temas como las partículas elementales, el DNA o el Big Bang, los matemáticos, en general, sólo consiguen hacer partícipes de sus experiencias y sus triunfos a sus propios cofrades. Confiamos en que, aunque obedezca en parte a razones intrínsecas, esta dificultad no es insuperable. El lenguaje y la visualización, manejados con pericia, pueden ser recursos indispensables en este empeño.

Antes de terminar quiero señalar que he aprovechado esta oportunidad para volver los ojos hacia mai propia labor como profesor y es alli donde he detectado las deficiencias a que he aludido. He tratado de superarlas, contando, por fortuna, con la ayuda de mis colegas, entre quienes he encontrado algunos de mis mejores maestros. Así he podido comprender que el campo de la enseñanza requiere aún mucha creatividad y también muchas virtudes. Alli no caben la arrogancia, el dogmatismo o la intransigencia. Es posible que reconociendo nuestras deficiencias ayudemos a otros a evitarlas. Sin olvidar que nuestros verdaderos defectos son aquellos de los cuales jamás somos conscientes.
Hacer comentarios mordaces o dar consejos es fácil, pero es difícil conocerse a si mismo.

Queriendo encontrar una sentencia que recoja mucho de lo que he querido expresar, me encuentro con un mandamiento pedagógico que era muy caro a Whitehead. No tratemos de enseñar demasiadas cosas. Y lo que enseñemos, enseñémoslo bien. En nuestro papel de maestros a veces queremos enseñar demasiado, es decir, exhibir nuestro conocimiento, corriendo el riesgo de saturar a nuestros alumnos con ideas inertes. Empecé recordando la conferencia sobre el Bien de Platón. Permítanme terminar con una cita de su diálogo Las Leyes.

Haciendo referencia a las matemáticas, Clinias le dice al Ateniense:

- Extranjero, me parece que recelas hablar sobre estas materias a causa del poco conocimiento que de ellas tenemos nosotros. Pero tu prevención es infundada. Prueba a decirnos tu pensamiento y que nuestra ignorancia no sea motivo para que nos ocultes algo.

Este, presumiblemente el mismo autor, replica:

- La razón que mencionas me causa, en efecto, alguna inquietud. Sin embargo temería mucho más habérmelas con otros, que hubieran estudiado mal. La ignorancia absoluta no es el mayor de los males ni el más temible, una vasta extensión de conocimientos mal digeridos es cosa mucho peor.

Y Clinas contesta: Dices verdad. $* * *$

Agradezco a los amigos que han querido acompañarme en esta ocasión y a todos los presentes por haber permanecido en el recinto hasta el final de este discurso. Espero que lo hayan disfrutado y que, dentro de poco, lo hayan refutado. 


\section{Panena Surcolosmbiana 16}

Quiero agradecer a la Universidad de Antioquía y a la Sociedad Colombiana de Matemáticas por la distinción de que he sido objeto.

Esta universidad, más que ninguna otra, ha pugnado siempre por el equilibrio entre ciencia y cultura. Su participación en este certamen es una muestra más de la claridad y firmeza de sus convicciones.
Y quiero mencionar a la Universidad Nacional porque, aunque debe fijar metas y plazos, también sabe esperar, paciente y confiada, a que alguien dibuje un cangrejo.

Alonso Takahashi Medellin, 26 de agosto de 1991. 